\title{
Clinical recommendations for the use of recombinant human erythropoietin in patients with hepatitis $C$ virus being treated with ribavirin
}

\author{
Morris Sherman MB BCh PhD FRCPC ${ }^{1}$, Lawrence Cohen MD MSc FRCPC ${ }^{2}$, Mary Anne Cooper MD FRCPC ${ }^{2}$, \\ Magdy Elkashab MD FRCPC ${ }^{3}$, Victor Feinman MD FRCPC ${ }^{4}$, David Fletcher MD FRCPC ${ }^{5}$, Nigel Girgrah MD FRCPC ${ }^{1}$, \\ Jenny Heathcote MB BS MD FRCPC ${ }^{6}$, Mark Levstik MB BCh FRCPC ${ }^{7}$, William B McNaull MB ChB MPhil FRSTM ${ }^{4}$, \\ David Wong MD FRCPC ${ }^{6}$, Florence Wong MB BS FRCPC ${ }^{1}$, Colina Yim RN ACNP MN ${ }^{6}$
}

\begin{abstract}
M Sherman, L Cohen, MA Cooper, et al. Clinical recommendations for the use of recombinant human erythropoietin in patients with hepatitis $\mathrm{C}$ virus being treated with ribavirin. Can J Gastroenterol 2006;20(7):479-485.
\end{abstract}

Today, combination antiviral therapy with pegylated interferon-alpha and ribavirin (RBV) allows many patients infected with hepatitis $\mathrm{C}$ virus (HCV) to achieve a sustained virological response, which is equivalent to cure. Data also support the clinical benefit of combination antiviral therapy in patients coinfected with HCV and $\mathrm{HIV}$, and in patients who have received a liver transplant.

Antiviral therapy with pegylated interferon-alpha and RBV is, however, associated with a high incidence and significant magnitude of anemia. This anemia may have several mechanisms, including bone marrow suppression and hemolysis. In addition, patients coinfected with HIV may have both pre-existing and RBV-associated anemia. Management of anemia in patients with HCV through RBV dose reduction or treatment discontinuation may compromise the effectiveness of treatment, because studies have demonstrated that treatment adherence or maintenance of antiviral therapy dose is an important predictor of sustained virological response.

Anemia associated with combination antiviral therapy in patients with $\mathrm{HCV}$ is frequently associated with an inadequate or blunted endogenous erythropoietin response. Accumulating evidence now supports the use of recombinant human erythropoietin ( $\mathrm{rHuEpo}$ ) to manage anemia in these patients, with the objective of maintaining the RBV dose, but clinical standards are lacking. The present article reviews the data relevant to the use of $\mathrm{rHuEpo}$ in this patient population and proposes a set of clinical practice standards to assist clinicians in selecting patients for $\mathrm{rHuEpo}$ and in implementing rHuEpo therapy effectively.

Key Words: Anemia; Hepatitis C virus; Recombinant human erythropoietin; Ribavirin

\section{Des recommandations cliniques pour l'usage d'érythropoiétine humaine recombinante chez les patients atteints du virus d'hépatite $C$ traités à la ribavirine}

De nos jours, la polythérapie antivirale à l'interféron pégylé alpha et à la ribavirine (RBV) permet à de nombreux patients infectés par le virus de l'hépatite $\mathrm{C}$ (VHC) de profiter d'une réaction virologique soutenue, équivalant à la guérison. Les données appuient également le bienfait clinique de la polythérapie antivirale chez les patients co-infectés par le VHC et le VIH et chez les patients greffés du foie.

La thérapie antivirale à l'interféron pégylé alpha et à la RBV s'associe toutefois à une forte incidence d'anémie de grande envergure. Cette anémie peut se manifester par divers mécanismes, y compris la suppression médullaire et l'hémolyse. De plus, les patients co-infectés par le VIH peuvent souffrir à la fois d'anémie préexistante et d'anémie causée par la RBV. La prise en charge de l'anémie chez les patients atteints du VHC par une réduction de la dose de RBV ou l'abandon du traitement peut compromettre l'efficacité du traitement. En effet, les études ont démontré que l'adhésion au traitement ou le maintien de la dose antivirale constituent des prédicteurs importants d'une réaction virologique soutenue.

L'anémie associée à la polythérapie antivirale chez les patients atteints du VHC s'associe souvent à l'insuffisance ou à l'émoussement de la réaction de l'érythropoiétine endogène. Les données probantes s'accumulent pour soutenir le recours à l'érythropoiétine humaine recombinante (rHuEpo) afin de prendre en charge l'anémie chez ces patients en vue de maintenir la dose de RBV, mais il n'existe pas de normes cliniques à cet effet. Le présent article analyse les données reliées à l'utilisation de rHuEpo au sein de cette population de patients et inclut une série de normes de pratique clinique pour aider les cliniciens à sélectionner les patients qui prendront de la rHuEpo et à implanter une thérapie efficace à la rHuEpo.
A

ntiviral therapy now allows many patients infected with hepatitis $\mathrm{C}$ virus (HCV) to achieve a sustained virological response (SVR), which is equivalent to cure (1). The highest response rates are achieved with a combination of pegylated interferon-alpha (PEG IFN- $\alpha$ ) and ribavirin (RBV). The recent publication Management of Viral Hepatitis: A Canadian Consensus Conference 2004, states that based on the improvements achieved in SVR with PEG IFN- $\alpha / R B V$ combination therapy, all HCV-infected patients should be evaluated for suitability for treatment (1). Combination antiviral therapy (PEG IFN- $\alpha$ plus RBV) is, however, associated with a significant incidence of anemia that may require RBV dose reduction or treatment discontinuation, thus compromising the effectiveness of treatment.

${ }^{1}$ Toronto General Hospital; '2 Sunnybrook and Women's College Health Sciences Centre and Faculty of Medicine, University of Toronto;

${ }^{3}$ North York General Hospital; ${ }^{4}$ Mount Sinai Hospital and Faculty of Medicine, University of Toronto; ${ }^{5}$ Maple Leaf Medical Clinic;

${ }^{6}$ Toronto Western Hospital and Faculty of Medicine, University of Toronto, Toronto; ${ }^{7}$ London Health Sciences Centre and Schulich School of

Medicine, University of Western Ontario, London, Ontario

Correspondence: Dr Morris Sherman, Toronto General Hospital, North Building 9-981, 585 University Avenue, Toronto, Ontario M5G 2 N2.

Telephone 416-340-4756, fax 416-591-2107, e-mail morris.sherman@uhn.on.ca

Received for publication January 13, 2006. Accepted February 17, 2006 
A growing body of evidence and increasing clinical experience now exist concerning the use of recombinant human erythropoietin ( $\mathrm{rHuEpo}$ ) to manage anemia in $\mathrm{HCV}$ patients treated with PEG IFN- $\alpha /$ RBV. However, practice standards do not yet exist. Therefore, a group of clinicians with expertise in managing patients with HCV have reviewed the available data and have proposed consensus clinical guidelines for the use of rHuEpo. Because all published data concerning the management of RBV-induced anemia in this population have been generated in clinical trials of epoetin alpha, the discussion focuses on that agent. No data are available for the use of darbepoetin alpha.

\section{RESPONSE TO COMBINATION ANTIVIRAL THERAPY FOR HCV}

The main predictors of response to combination antiviral therapy with PEG IFN- $\alpha /$ RBV are viral genotype, viral load and treatment adherence. SVR rates of $78 \%$ to $82 \%$ have been achieved in patients infected with HCV genotypes 2 and 3, whereas the SVR rate for other genotypes (mainly genotype 1) is approximately $44 \%(2,3)$. Viral loads below $800,000 \mathrm{IU} / \mathrm{mL}$ are associated with higher SVRs than higher viral loads. Finally, treatment adherence is an important factor affecting outcome. Dose reductions may be used to manage treatment side effects such as anemia. Minor reductions in total dose, which still allow for more than $80 \%$ of the total dose to be administered, reduce SVR slightly, whereas greater reductions reduce SVR to a greater degree (4). Premature treatment discontinuation is associated with very low SVR rates. The extent to which timing of dose reduction and discontinuation affects SVR has, however, not yet been fully explored.

In patients infected with HCV genotype 1, the lack of early virological response (EVR), measured after 12 weeks of therapy, reliably predicts lack of SVR $(4,5)$. Patients who achieve EVR have a $65 \%$ to $72 \%$ chance of achieving SVR, whereas the chance of SVR in those who do not achieve EVR is less than 3\%. Measurement of EVR is not helpful in patients infected with HCV genotype 2 or 3 because $97 \%$ of these patients achieve EVR.

Clinical studies have identified effective PEG IFN- $\alpha /$ RBV regimens for patients infected with different HCV genotypes. The Canadian Consensus Conference also recommended that patients who have not responded or who have relapsed after successful non-PEG IFN- $\alpha$ antiviral treatment should receive a standard dose and duration of PEG IFN- $\alpha /$ RBV (1). Patients coinfected with HCV and HIV should receive full-dose combination therapy with aggressive supportive therapy to treat drug-induced side effects and prevent reductions in SVR.

\section{IMPORTANCE OF TREATMENT ADHERENCE}

Several studies have demonstrated the importance of treatment adherence to overall treatment success. McHutchison et al (6) reviewed data from previous trials of combination therapy with IFN- $\alpha 2 b$ or PEG IFN- $\alpha$ plus RBV in 1521 patients infected with HCV genotype 1. Treatment was verified from drug records and patient diaries. Patients were divided into two groups: those who took at least $80 \%$ of the total dose of both drugs for at least $80 \%$ of the expected treatment duration, and those who did not. Patients who achieved $80 \%$ adherence had SVR rates of $52 \%$ for IFN- $\alpha /$ RBV and $63 \%$ for PEG IFN- $\alpha /$ RBV, whereas patients who did not achieve $80 \%$ adherence had SVR rates of $18 \%$ and $25 \%$, respectively. The authors concluded that adherence enhances the likelihood of EVR.

Davis et al (5) examined degrees of viral inhibition during the initial weeks of treatment among patients with HCV treated with PEG IFN- $\alpha /$ RBV combination therapy with the objective of identifying factors associated with eventual lack of response. The authors found that the best predictor of SVR was an EVR comprising a 2 log drop in HCV RNA after 12 weeks of therapy. Between $69 \%$ and $76 \%$ of patients achieved EVR, and $67 \%$ to $80 \%$ of patients achieving EVR went on to achieve SVR. Patients not achieving EVR as defined in the present analysis do not respond to additional drug therapy.

These studies demonstrate the importance of maintenance of antiviral dose or treatment adherence to EVR and to SVR, especially for patients infected with HCV genotype 1.

\section{CONSIDERATIONS IN TREATING LIVER TRANSPLANT PATIENTS WITH HCV}

Hepatitis C after liver transplantation presents a treatment challenge. First, the disease progresses more rapidly than in the nontransplant setting. Second, although precise response rates are not known, it is clear that response rates are lower than the nontransplant setting.

Berenguer et al (7) evaluated the natural history of HCV disease progression in the orthotopic liver transplant (OLT) population by means of biopsies of 284 patients and found that fibrosis scores increased linearly with time from transplantation (Figure 1).

Fibrosis also progresses much more rapidly in patients after OLT than in patients who have not received a liver transplant (7). The time interval from infection to cirrhosis, usually between 20 and 40 years in non-OLT patients, is decreased to between nine and 12 years in OLT recipients. In an attempt to identify factors affecting the progression of fibrosis, Chopra et al (8) studied 58 patients with HCV who had undergone OLT. The study found that genotype was a factor, with genotype 1a being associated with an increased risk of fibrosis, and that cytomegalovirus infection also increased the rate of fibrosis.

Dumortier et al (9) reported on a pilot study involving 12 months of combination therapy with PEG IFN $-\alpha$ and RBV in 20 patients transplanted for HCV. The time between transplantation and antiviral therapy was 28 months and $80 \%$ of the patients were infected with genotype 1 . Overall, $75 \%$ of patients had a biochemical response and $55 \%$ a virological response. In nine patients, the virological response persisted six months after treatment. The mean METAVIR score for activity and fibrosis decreased from A1.8 F2.2 before treatment to A0.3 F1.6 at the end of treatment. The RBV dose was reduced in 16 patients, 13 of whom experienced dose reductions for anemia. The PEG IFN- $\alpha$ dose was reduced in six patients. The authors concluded that combination antiviral therapy was beneficial for HCV recurrence in patients transplanted for HCV but anemia limited RBV dosing.

Other studies have also shown that treatment is limited by toxicity, mainly bone marrow suppression and anemia (10-12). Given that patients with recurrent HCV after transplantation may not have a second chance at therapy, it is important to maximize the likelihood of a response, including maintaining maximal doses of both IFN and RBV. Appropriate 


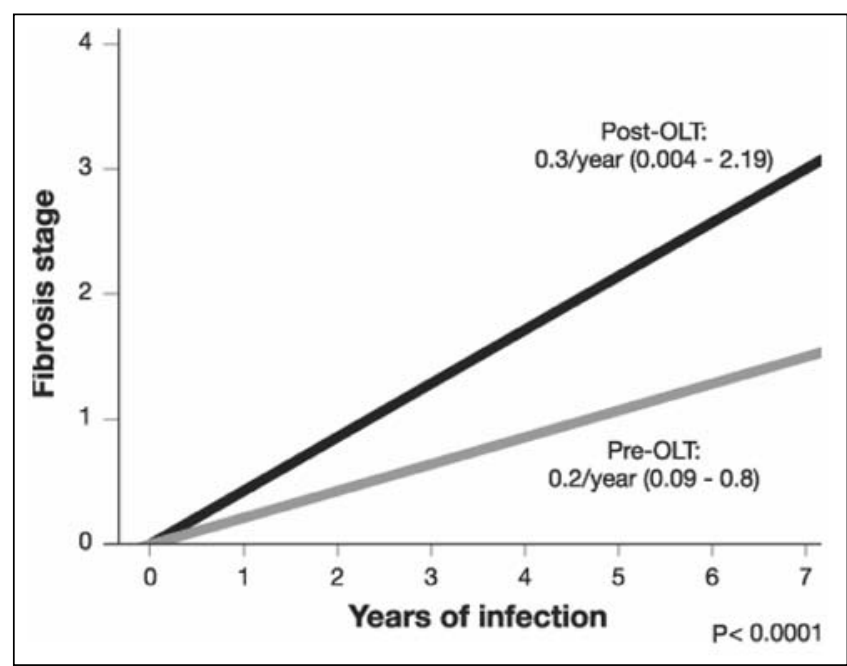

Figure 1) Progression of fibrosis in patients with hepatitis $C$ virus infection pre-orthotopic liver transplantation (pre-OLT) and post-OLT according to duration of infection. Adapted from reference 7

management of anemia and bone marrow suppression may improve the ability to deliver maximal doses of therapy.

\section{CONSIDERATIONS IN TREATING HCV/HIV COINFECTED PATIENTS}

Similar considerations apply to patients with $\mathrm{HIV} / \mathrm{HCV}$ coinfection. Liver disease tends to progress more rapidly $(13,14)$ and response rates to treatment are decreased compared with those without HIV infection $(15,16)$.

Estimates of the prevalence of HCV/HIV coinfection vary. Globally, nearly one-third of patients infected with HIV may be coinfected with HCV (10). Since the advent of highly active antiretroviral therapy and longer survival of patients infected with HIV, HCV has become a major cause of morbidity and mortality in patients infected with HIV (17). Coinfected individuals tend to have higher viral loads and relatively more severe $\mathrm{HCV}$ disease $(13,14)$; they also experience more rapid progression of hepatic fibrosis and an increased incidence of cirrhosis and death due to liver disease.

Given that good response rates are more difficult to achieve, the use of supportive treatment to maintain maximal doses of IFN and RBV is important.

\section{COMBINATION ANTIVIRAL THERAPY AND ANEMIA}

Anemia is a common side effect that can jeopardize treatment adherence and EVR, thus potentially compromising the effectiveness of treatment. Gaeta et al (18) performed a multicentre retrospective study to compare the 'real-world' discontinuation rate for combination HCV therapy with the $27 \%$ seen in randomized controlled trials. They enrolled 441 consecutive patients scheduled to receive IFN- $\alpha / \mathrm{RBV}$ combination therapy at five centres. The authors found that adverse events resulted in discontinuation in 108 (24.5\%) patients, discontinuation was higher in the first six months and the reason for discontinuation was anemia in approximately one-third of patients.

The anemia seen in patients receiving combination antiviral therapy may have several mechanisms (19). IFN- $\alpha$ suppresses bone marrow, reducing red blood cell production,

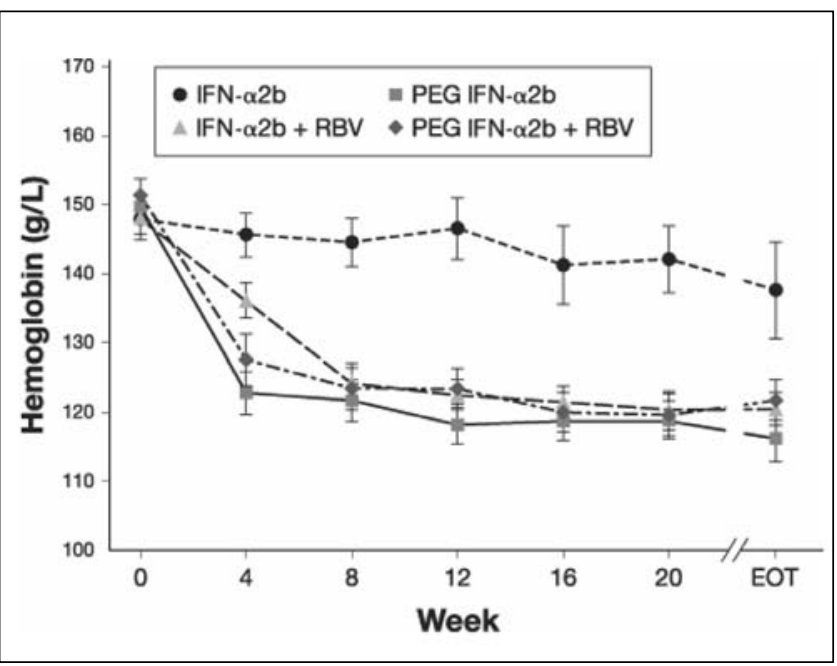

Figure 2) Impact of four hepatitis $C$ antiviral treatment regimens on hemoglobin levels during 24 to 48 weeks of therapy. EOT End of therapy; PEG IFN- $\alpha 2 b$ Pegylated interferon-alpha2b; RBV Ribavirin. Adapted from reference 21

whereas RBV causes a dose-dependent hemolytic anemia. Thus, combination therapy not only decreases red cell mass but reduces the compensatory reticulocytosis expected with hemolysis.

The magnitude of decrease of hemoglobin $(\mathrm{Hb})$ has been evaluated in a retrospective analysis of data from two studies of combination therapy (20). Among the 594 patients for whom data were available, initial $\mathrm{Hb}$ levels exceeded $120 \mathrm{~g} / \mathrm{L}$ among women $(\mathrm{n}=208)$ and $130 \mathrm{~g} / \mathrm{L}$ among men $(\mathrm{n}=386)$. Hb decreased by at least $30 \mathrm{~g} / \mathrm{L}$ in $54 \%$ of the patient population and by more than $25 \%$ from baseline in approximately $28 \%$ of patients. Almost $10 \%$ of men and $7 \%$ of women experienced an $\mathrm{Hb}$ decrease of at least $50 \mathrm{~g} / \mathrm{L}$. These trials indicate both a high incidence and significant magnitude of anemia in patients treated with combination antiviral therapy.

A study in 133 patients receiving antiviral treatment for HCV with IFN- $\alpha$ or PEG IFN- $\alpha$ alone or in combination with RBV evaluated the impact of treatment on hematopoiesis (21). In the groups receiving combination therapy, $\mathrm{Hb}$ decreased by $20 \mathrm{~g} / \mathrm{L}$ or $30 \mathrm{~g} / \mathrm{L}$ by four weeks and remained low throughout therapy, whereas in the group receiving IFN- $\alpha$ monotherapy, $\mathrm{Hb}$ decreased only slightly by eight weeks but also remained decreased throughout therapy (Figure 2). $\mathrm{Hb}$ decreased substantially more with PEG IFN- $\alpha$ monotherapy than with IFN- $\alpha$ monotherapy. As Hb decreased in the groups receiving combination therapy, the concentration of endogenous erythropoietin increased.

However, the increase in endogenous erythropoietin may be inadequate. Balan et al (22) performed a multicentre observational study that included 97 evaluable patients. The authors found the endogenous erythropoietin response to anemia to be decreased in this patient population compared with patients with iron deficiency anemia.

\section{ANEMIA IN HCV/HIV COINFECTED PATIENTS} Combination therapy for $\mathrm{HCV}$ in coinfected individuals is associated with a more profound anemia than seen in monoinfected patients (20). This situation is compounded by a high prevalence of pretreatment anemia and by the potential 


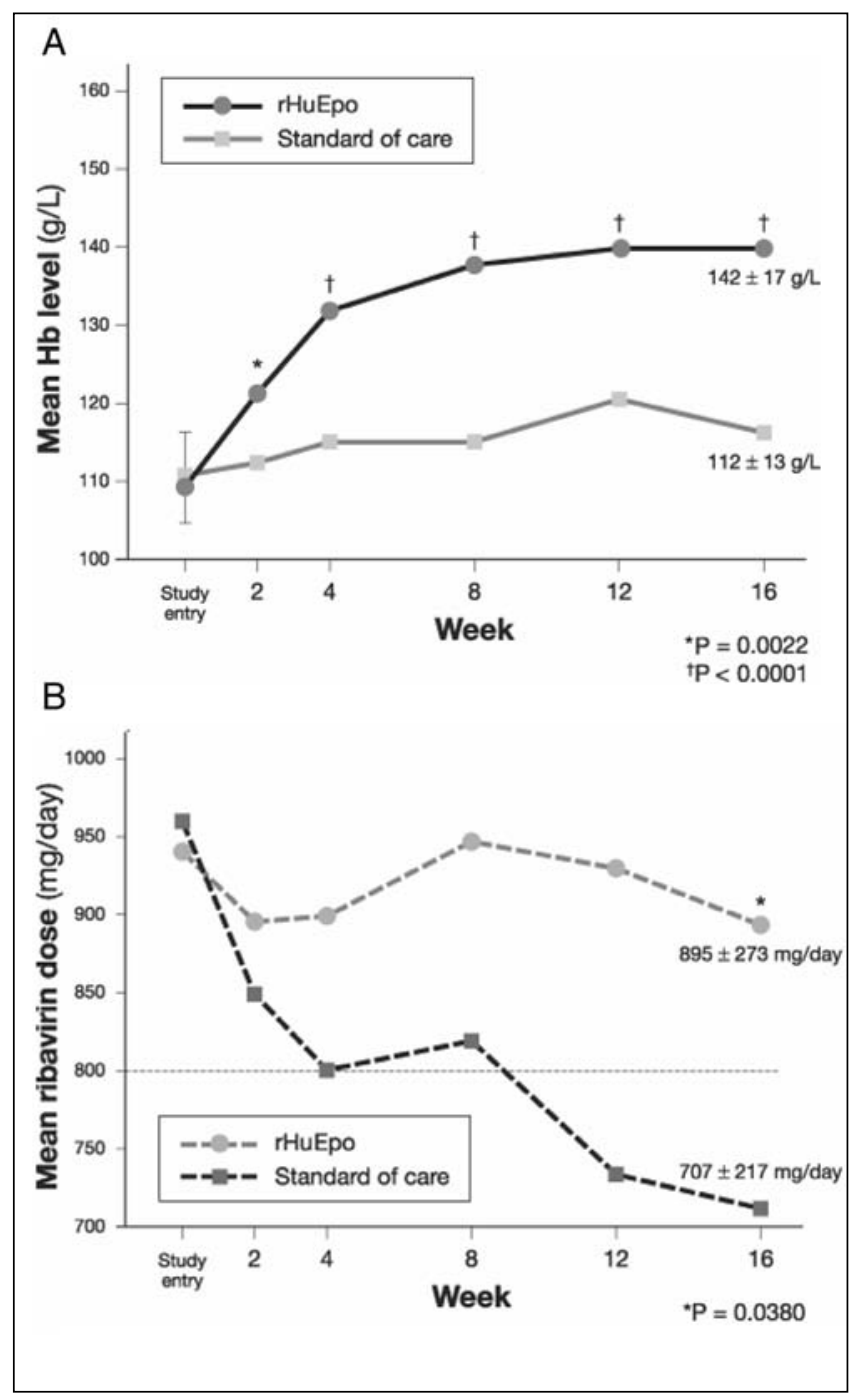

Figure 3) Mean hemoglobin ( $\mathrm{Hb}$ ) levels (A) and mean ribavirin dose (B) with recombinant human erythropoietin ( $\mathrm{rHuEpo})$ and standard of care in patients with hepatitis $\mathrm{C}$ virus being treated with combination therapy with ribavirin plus interferon-alpha. Adapted from reference 24

need for treatment with other medications causing anemia. Sulkowski et al (23) have shown that rHuEpo use will effectively correct anemia associated with HCV treatment and allows maintenance of RBV dosing.

\section{rHuEpo AND ANEMIA MANAGEMENT IN HCV PATIENTS RECEIVING COMBINATION THERAPY}

Clinical studies have now demonstrated that treatment with $\mathrm{rHuEpo}$ can maintain $\mathrm{Hb}$ levels in patients treated with combination antiviral therapy for $\mathrm{HCV}$. In the past, low $\mathrm{Hb}$ disqualified patients from receiving antiviral therapy for $\mathrm{HCV}$ due to the potential for worsening anemia. Today, however, patients with pre-existing anemia and those who develop anemia as a result of treatment can be treated with rHuEpo. This may obviate the need for RBV dose reduction, improve treatment adherence and improve the likelihood of SVR.

Dieterich et al (24) performed an open-label, parallelgroup study at seven centres to determine the efficacy of
rHuEpo in treating anemia and minimizing RBV dose reduction in patients with $\mathrm{HCV}$ receiving IFN- $\alpha / \mathrm{RBV}$ combination therapy. The study enrolled 64 patients with a maximum $\mathrm{Hb}$ level of $120 \mathrm{~g} / \mathrm{L}$ during the first 24 weeks of antiviral therapy and randomly assigned them to receive rHuEpo 40,000 IU subcutaneously weekly or standard of care (SOC) for anemia management. SOC consisted of an RBV dose reduction to $600 \mathrm{mg} /$ day when $\mathrm{Hb}$ dropped to less than $100 \mathrm{~g} / \mathrm{L}$ and later RBV discontinuation at an $\mathrm{Hb}$ level of $85 \mathrm{~g} / \mathrm{L}$ with transfusion (24). The primary end point was the change in $\mathrm{Hb}$ level and the secondary end point was the RBV dosage, both measured from baseline to week 16 of treatment (Figure 3).

The mean increase in $\mathrm{Hb}$ was $28 \mathrm{~g} / \mathrm{L}$ for $\mathrm{rHuEpo}$ versus $4 \mathrm{~g} / \mathrm{L}$ for SOC $(\mathrm{P}<0.0001)$ and the mean change in RBV dose was $-34 \mathrm{mg} /$ day for $\mathrm{rHuEpo}$ compared with $-146 \mathrm{mg} /$ day for SOC $(\mathrm{P}=0.060)$. The mean $\mathrm{Hb}$ in the $\mathrm{rHuEpo}$ group at week $16(138 \mathrm{~g} / \mathrm{L})$ was significantly higher $(\mathrm{P}<0.0001)$ than in the SOC group $(114 \mathrm{~g} / \mathrm{L})$. From week 4 onward, significantly more patients in the rHuEpo group than in the SOC group had no RBV dose reductions $(\mathrm{P}<0.011)$. By the conclusion of the study, $83 \%$ of patients treated with $\mathrm{rHuEpo}$ had maintained an RBV dose of at least $800 \mathrm{mg} /$ day compared with $54 \%$ of patients in the SOC group $(\mathrm{P}=0.022)$. This result may be clinically beneficial because evidence indicates that RBV doses below $800 \mathrm{mg} /$ day may be associated with a decreased likelihood of SVR.

The authors also found rHuEpo to be well-tolerated in this population (24). The study was neither designed nor powered to assess quality of life (QoL); however, QoL data were collected for descriptive purposes. Baseline values for both groups indicated comparable levels of existing impairment, and QoL improvement at 16 weeks was greater for the rHuEpo group than the SOC group. The QoL changes were both qualitatively and quantitatively similar to those seen in anemic cancer patients and HIV patients treated with rHuEpo.

Afdhal et al (25) performed a prospective, double-blind randomized controlled trial of rHuEpo 40,000 IU once weekly versus placebo in patients receiving IFN- $\alpha / \mathrm{RBV}$ or PEG IFN- $\alpha /$ RBV combination therapy. The objectives of the study were to determine whether rHuEpo could maintain RBV dose, improve $\mathrm{QoL}$ and increase $\mathrm{Hb}$ in anemic HCV-infected patients. The trial was designed with an eight-week doubleblind phase (DBP) followed by an eight-week open-label phase (OLP) during which placebo patients were crossed over to rHuEpo. The study enrolled 185 patients who were receiving combination therapy and who had a maximum $\mathrm{Hb}$ level of $120 \mathrm{~g} / \mathrm{L}$. The mean $\mathrm{Hb}$ at randomization was $108 \mathrm{~g} / \mathrm{L}$ in both groups. During the trial, the RBV dose was increased or decreased based on Hb levels. During the DBP, $4 \%$ of the $\mathrm{rHuEpo}$ group and $3 \%$ of the placebo group discontinued HCV treatment, and during the OLP, $3 \%$ of the rHuEpo group and $6 \%$ of the original placebo group discontinued HCV treatment.

At the end of the DBP, $88 \%$ of rHuEpo patients had maintained their RBV dose compared with $60 \%$ of placebo patients $(\mathrm{P}<0.0001)$ (25). At the end of the OLP, $78 \%$ of the original $\mathrm{rHuEpo}$ group were receiving an $\mathrm{RBV}$ dose that was at least equivalent to the starting dose compared with $64 \%$ of patients in the original placebo group. Patients in the original placebo group also had a significant increase in RBV dose $(\mathrm{P}<0.001)$ during the OLP. 
Mean QoL scores improved significantly in the $\mathrm{rHuEpo}$ group compared with the placebo group from randomization to the end of the DBP (25). Scores increased similarly for patients who crossed over from placebo to the OLP. Mean $\mathrm{Hb}$ increased by $22 \mathrm{~g} / \mathrm{L}$ in the rHuEpo group to a mean of $130 \mathrm{~g} / \mathrm{L}$ and by $1 \mathrm{~g} / \mathrm{L}$ in the placebo group to a mean of $109 \mathrm{~g} / \mathrm{L}$. A similar improvement was seen during the OLP for the placebo group, and the $\mathrm{Hb}$ was maintained in the epoetin group. The study was not designed to assess the effect of $\mathrm{rHuEpo}$ treatment on SVR. However, more patients in the rHuEpo group were able to maintain the RBV dose.

Pockros et al (26) performed a detailed analysis of the Afdhal et al (25) QoL data. The objectives of the study were to compare health-related quality of life (HRQL) of patients in the study with that of the general population and patients with other chronic conditions, including untreated HCV, congestive heart failure, clinical depression and type II diabetes, and to evaluate retrospectively the relationship between HRQL and Hb levels. HRQL is now known to be impaired in patients with HCV to a similar extent to that seen in cancer patients undergoing chemotherapy $(27,28)$. In cancer patients, HRQL directly correlates with $\mathrm{Hb}$ levels, and rHuEpo treatment not only increases $\mathrm{Hb}$ but improves HRQL domains such as energy, activity and overall QoL.

In this study, HRQL was assessed at randomization, at the end of the DBP and at the end of the OLP using two instruments: the Short Form-36 (SF-36) and the linear analogue self-assessment scale. The SF-36 is a validated and widely used HRQL instrument and the linear analogue selfassessment scale has been extensively used to measure HRQL in anemic patients. Mean SF-36 scores of anemic HCVinfected patients receiving combination therapy at study randomization were significantly lower than those of both the general population and patients with untreated HCV infection. In addition, scores on several functional domains were lower than for all comparison populations. Cirrhosis was evaluated as a contributing factor, but values were not different for patients with or without cirrhosis. Patients with the greatest increases in $\mathrm{Hb}$ from randomization to the end of the DBP also had the greatest improvements in HRQL, and $\mathrm{Hb}$ increases of at least $20 \mathrm{~g} / \mathrm{L}$ were associated with significant improvements on both scales. In contrast, patients whose $\mathrm{Hb}$ decreased during the DBP generally experienced a decrease in HRQL. Hb was a significant independent predictor of changes in HRQL and the most consistent predictor for HRQL improvement. The study was not designed to evaluate SVR, and patients were not stratified by genotype or other factors known to influence SVR. Nevertheless, at six-month follow-up, $53 \%$ of the rHuEpo group had achieved SVR compared with $45 \%$ of the placebo group.

In addition to the above studies, that did not evaluate the effect of rHuEpo on SVR, there are now preliminary data that indicate that the use of $\mathrm{rHuEpo}$ to treat $\mathrm{RBV}$-induced anemia improves SVR rates as well as maintaining $\mathrm{Hb}$ and RBV dose levels (29). Furthermore, at least one costefficacy analysis has demonstrated that this is a costeffective form of treatment (30).

\section{INADEQUATE RESPONSE TO rHuEpo}

An inadequate response to rHuEpo has been noted in some dialysis patients in the chronic renal failure population (31). The most common cause is absolute or functional iron

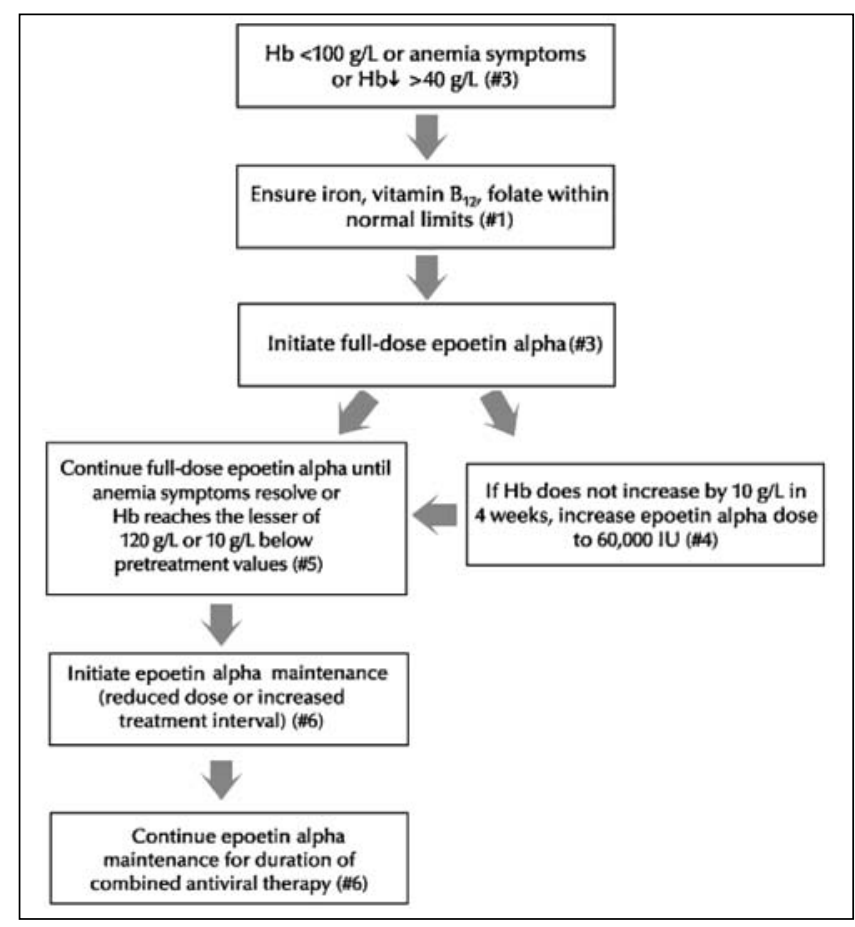

Figure 4) Approach to the use of epoetin alpha in the management of anemia associated with combination antiviral therapy in patients infected with hepatitis $\mathrm{C}$ virus. Hb Hemoglobin

deficiency, but chronic inflammation may also reduce response, leading to a need for higher rHuEpo dose levels. Chronic inflammation may also be a cause of reduced response to $\mathrm{rHuEpo}$ in patients with HCV. These causes of inadequate response to rHuEpo must be differentiated from antibody-mediated pure red cell aplasia (PRCA), a rare occurrence. Stravitz et al (32) reported on a case of PRCA with resulting transfusion dependence, which resolved 16 weeks after discontinuing rHuEpo. Analysis of stored serum samples identified a decrease in erythropoietin concentrations from supraphysiological levels at week 12 to undetectable levels at week 24 of therapy, along with a parallel rise in the titre of neutralizing antibodies. Antierythropoietin antibodies cross-react with endogenous erythropoietin and with recombinant preparations. As a result, erythropoietin treatment should be discontinued rather than switched to another product.

PRCA tends to occur late after initiation of erythropoietin treatment, whereas other causes of inadequate epoetin response are usually operative from treatment initiation. A paradoxical $\mathrm{Hb}$ decrease after a response to erythropoietin may indicate the development of PRCA and should prompt discontinuation of rHuEpo and antiviral therapy.

\section{CONSENSUS RECOMMENDATIONS: CLINICAL STANDARDS FOR THE USE OF rHuEpo}

The use of rHuEpo is medically appropriate in certain clinical situations in patients infected with HCV and treated with combination antiviral therapy. The following recommendations reflect a group consensus on clinical standards for use of rHuEpo. These recommendations are based on the available evidence and on clinical experience of the discussion group. Figure 4 summarizes the recommended approach to the management of anemia related to combination antiviral therapy in this patient population. 
Clinical considerations in deciding on $\mathrm{rHuEpo}$ treatment

In all patients, the decision to initiate rHuEpo treatment requires consideration of the risks of treatment failure with reduction of $\mathrm{RBV}$ dose, the cost of $\mathrm{rHuEpo}$ and the possible complications resulting from the use of $\mathrm{rHuEpo}$. Patients with a high likelihood of response, such as those infected with HCV genotype 2 or 3, may tolerate RBV dose reduction without much decrease in the likelihood of achieving SVR. In contrast, dose reduction should be avoided, if possible, in patients in whom the response rate is lower and in whom a maximal effort is required to increase the individual's chance of response. This group includes patients who are HIV-positive and those who have received a liver transplant. Similarly, dose reduction should also be avoided in patients for whom achieving response is more urgent, such as individuals with cirrhosis or advanced age combined with stage 3 fibrosis, because these patients may not have a second opportunity for treatment with new agents.

Reduction in RBV dose appears to be more critical to sustained response rates if it occurs in the first 12 weeks of therapy. As a result, maintenance of $\mathrm{Hb}$ levels during the first 12 weeks of therapy is more important than at later stages during treatment. However, RBV dose reductions after 12 weeks may also reduce the overall response rate.

\section{Recommendation 1: Deficiencies possibly contributing to anemia}

All HCV patients treated with RBV should be assessed for other causes of anemia, including iron, folate and vitamin $B_{12}$ deficiencies, and any deficiencies identified should be corrected. Folic acid supplementation (5 mg/day) is appropriate because RBV-induced hemolysis may contribute to folate deficiency.

\section{Recommendation 2: Assessment}

All patients who receive RBV should have a baseline assessment for clinical risks associated with anemia, such as poor exertional tolerance, which may indicate underlying cardiovascular or pulmonary disease. Clinical parameters and symptoms related to anemia, such as fatigue and increased heart rate, should be documented before treatment. During treatment, patients should be routinely assessed for the development of new anemia-related symptoms.

\section{Recommendation 3: Indications for treatment with epoetin alpha}

There are two forms of erythropoietin available in Canada, epoetin alpha and darbepoetin, which is a modified form of human erythropoietin. In the absence of data supporting the use of darbepoetin alpha, these recommendations apply to only the use of epoetin alpha. The following are recommended indications for treatment with epoetin alpha:

- a decline in $\mathrm{Hb}$ from baseline of more than $40 \mathrm{~g} / \mathrm{L}$,

- Hb concentration of $100 \mathrm{~g} / \mathrm{L}$ or less; or

- symptomatic anemia, which may occur at any $\mathrm{Hb}$ concentration following a rapid fall in $\mathrm{Hb}$ concentration.

\section{Recommendation 4: Epoetin alpha regimens}

The following are recommended possible initial epoetin alpha regimens:

- dose of 40,000 IU subcutaneously per week; or
- initiation of treatment at 20,000 IU subcutaneously per week with dose increase based on response.

Epoetin alpha dose may be increased to a maximum of 60,000 IU subcutaneously per week if an inadequate response is seen after four weeks of treatment with 40,000 IU subcutaneously per week.

\section{Recommendation 5: Epoetin alpha treatment duration}

Full-dose epoetin alpha treatment should be maintained until either of the following:

- resolution of anemia-related symptoms or

- recovery of $\mathrm{Hb}$ concentration to the lesser of $120 \mathrm{~g} / \mathrm{L}$ or $10 \mathrm{~g} / \mathrm{L}$ below pretreatment values.

It is not necessary to treat until $\mathrm{Hb}$ returns to baseline levels. Hb usually decreases again if epoetin alpha is discontinued during combined antiviral treatment. Therefore, consideration should be given to epoetin alpha maintenance therapy.

Recommendation 6: Epoetin alpha maintenance treatment Once the $\mathrm{Hb}$ has recovered or the symptoms of anemia have resolved, it is recommended that the dose of epoetin alpha be reduced or the treatment interval lengthened to maintain $\mathrm{Hb}$ recovery during continued combination antiviral treatment.

\section{Recommendation 7: Retreatment of previous antiviral treatment failures}

Patients who developed symptomatic anemia with a prior course of antiviral treatment should be started on epoetin alpha when treatment with IFN and RBV is initiated. Approval for reimbursement should be sought before starting treatment.

Recommendation 8: Patients with coronary artery disease Patients with cardiovascular problems may be less tolerant of anemia, may risk poorer outcomes with RBV dose reductions and may experience more adverse events with epoetin alpha treatment. These patients may be poor candidates for antiviral therapy. However, if treatment with PEG IFN- $\alpha / \mathrm{RBV}$ is initiated, the decision to treat these patients with epoetin alpha should be individualized and if the benefits of epoetin alpha treatment are thought to outweigh the risks, epoetin alpha treatment should be initiated with caution.

\section{Recommendation 9: PRCA}

The magnitude of the risk of PRCA is not known currently but the potential for PRCA should be borne in mind when considering epoetin alpha treatment and patients should be informed of the risks. Patients in whom $\mathrm{Hb}$ continues to fall despite administration are at risk for PRCA; these patients should have epoetin alpha and RBV withdrawn and should have the effects of drug withdrawal on $\mathrm{Hb}$ monitored.

These recommendations were achieved by consensus among physicians from Toronto and London, Ontario, who are experienced in the management of patients with chronic $\mathrm{HCV}$, including those coinfected with HIV and those who have received a liver transplant. Although these recommendations have been developed in Ontario, they are likely to be applicable elsewhere in Canada.

No attempt was made to evaluate the cost-effectiveness of epoetin alpha use. 
This document represents the opinions of the authors and is not a consensus statement.

DISCLOSURES: Dr Sherman is a speaker for and a member of the advisory boards of Hoffmann-La Roche Ltd, Bristol-Myers Squibb Canada and Gilead Canada. He is also a member of the advisory board of Novartis Pharmaceuticals Canada Inc. Dr Heathcote is a member of the medical advisory board of Hoffmann-La Roche Ltd, Schering Canada Inc and Axcan Pharma. She is also supported by unrestricted grants from Hoffmann-La Roche Ltd, Schering Canada Inc and Axcan Pharma, as well as a restricted grant from Schering Canada Inc. Dr Wong is a consultant and speaker for Hoffmann-La Roche Ltd and a speaker for Axcan Pharma, Gilead Sciences, Ortho Biotech and Schering Canada Inc. Dr Feinman has received consulting fees from the advisory boards of Gilead Canada, Ortho Biotech and Johnson \& Johnson Inc, as well as Schering Canada Inc. Dr Yim is a member of the nurses advisory board for HoffmannLa Roche Ltd and Ortho Biotech. Dr Levstik has participated in clinical trials and advisory boards for Schering Canada Inc, Hoffmann-La Roche Ltd and Wyeth Pharmaceuticals. He has also participated on the advisory board for Ortho Biotech.

\section{REFERENCES}

1. Sherman M, Bain V, Villeneuve JP, et al. Management of Viral Hepatitis: A Canadian Consensus Conference 2004. The Public Health Agency of Canada. <http://www.phac-aspc.gc.ca> (Version current at September 21, 2005).

2. Manns MP, McHutchison JG, Gordon SC, et al. Peginterferon alfa- $2 \mathrm{~b}$ plus ribavirin compared with interferon alfa- $2 \mathrm{~b}$ plus ribavirin for initial treatment of chronic hepatitis $\mathrm{C}$ : A randomised trial. Lancet 2001;358:958-65.

3. Fried MW, Shiffman ML, Reddy KR, et al. Peginterferon alfa-2a plus ribavirin for chronic hepatitis $C$ virus infection. N Engl J Med 2002;347:975-82.

4. Ferenci P, Fried MW, Shiffman ML, et al. Predicting sustained virological responses in chronic hepatitis $\mathrm{C}$ patients treated with peginterferon alfa-2a (40 KD)/ribavirin. J Hepatol 2005;43:425-33.

5. Davis GL, Wong JB, McHutchison JG, Manns MP, Harvey J, Albrecht J. Early virologic response to treatment with peginterferon alfa- $2 \mathrm{~b}$ plus ribavirin in patients with chronic hepatitis C. Hepatology 2003;38:645-52.

6. McHutchison JG, Manns M, Patel K, et al. Adherence to combination therapy enhances sustained response in genotype-1-infected patients with chronic hepatitis C. Gastroenterology 2002;123:1061-9.

7. Berenguer M, Ferrell L, Watson J, et al. HCV-related fibrosis progression following liver transplantation: Increase in recent years. J Hepatol 2000;32:673-84.

8. Chopra KB, Demetris AJ, Blakolmer K, et al. Progression of fibrosis in patients with chronic hepatitis $\mathrm{C}$ after orthotopic liver transplantation. Transplantation 2003;76:1487-91.

9. Dumortier J, Scoazec JY, Chevallier P, Boillot O. Treatment of recurrent hepatitis $\mathrm{C}$ after liver transplantation: A pilot study of peginterferon alfa- $2 \mathrm{~b}$ and ribavirin combination. J Hepatol 2004;40:669-74.

10. Babatin M, Schindel L, Burak KW. Pegylated-interferon alpha $2 b$ and ribavirin for recurrent hepatitis $\mathrm{C}$ after liver transplantation: From a Canadian experience to recommendations for therapy. Can J Gastroenterol 2005;19:359-65

11. Toniutto P, Fabris C, Fumo E, et al. Pegylated versus standard interferon-alpha in antiviral regimens for post-transplant recurrent hepatitis C: Comparison of tolerability and efficacy. J Gastroenterol Hepatol 2005;20:577-82

12. Rodriguez-Luna H, Khatib A, Sharma P, et al. Treatment of recurrent hepatitis $\mathrm{C}$ infection after liver transplantation with combination of pegylated interferon alpha $2 \mathrm{~b}$ and ribavirin: An open-label series. Transplantation 2004;77:190-4.

13. Benhamou Y, Bochet M, Di Martino V, et al. Liver fibrosis progression in human immunodeficiency virus and hepatitis $\mathrm{C}$ virus coinfected patients. The Multivirc Group. Hepatology 1999;30:1054-8.

14. Kramer JR, Giordano TP, Souchek J, Richardson P, Hwang LY, El-Serag HB. The effect of HIV coinfection on the risk of cirrhosis and hepatocellular carcinoma in U.S. veterans with hepatitis C. Am J Gastroenterol 2005;100:56-63.

15. Torriani FJ, Rodriguez-Torres M, Rockstroh JK, et al. Peginterferon alfa-2a plus ribavirin for chronic hepatitis $\mathrm{C}$ virus infection in HIV-infected patients. N Engl J Med 2004;351:438-50.

16. Carrat F, Bani-Sadr F, Pol S, et al. ANRS HCO2 RIBAVIC Study Team. Pegylated interferon alfa- $2 \mathrm{~b}$ vs standard interferon alfa- $2 \mathrm{~b}$, plus ribavirin, for chronic hepatitis C in HIV-infected patients: A randomized controlled trial. JAMA 2004;292:2839-48.

17. Salmon-Ceron D, Lewden C, Morlat P, et al. The Mortality 2000 study group. Liver disease as a major cause of death among HIV infected patients: Role of hepatitis $\mathrm{C}$ and $\mathrm{B}$ viruses and alcohol. J Hepatol 2005;42:799-805.

18. Gaeta GB, Precone DF, Felaco FM, et al. Premature discontinuation of interferon plus ribavirin for adverse effects: A multicentre survey in 'real world' patients with chronic hepatitis C. Aliment Pharmacol Ther 2002;16:1633-9.

19. Sulkowski MS. Anemia in the treatment of hepatitis $C$ virus infection. Clin Infect Dis 2003;37(Suppl 4):315-22.

20. Sulkowski MS, Wasserman R, Brooks L, Ball L, Gish R. Changes in haemoglobin during interferon alpha-2b plus ribavirin combination therapy for chronic hepatitis $\mathrm{C}$ virus infection. J Viral Hepat 2004;11:243-50.

121.Schmid M, Kreil A, Jessner W, et al. Suppression of haematopoiesis during therapy of chronic hepatitis $\mathrm{C}$ with different interferon alpha mono and combination therapy regimens. Gut 2005;54:1014-20.

22. Balan V, Schwartz D, Wu GY, et al. Erythropoietic response to anemia in chronic hepatitis $\mathrm{C}$ patients receiving combination pegylated interferon/ribavirin. Am J Gastroenterol 2005;100:299-307.

23. Sulkowski MS, Dieterich DT, Bini EJ, et al. For the HIV/HCV Coinfection Study Group. Epoetin alfa once weekly improves anemia in HIV/hepatitis $\mathrm{C}$ virus-coinfected patients treated with interferon/ribavirin: A randomized controlled trial. J Acquir Immune Defic Syndr 2005;39:504-6.

24. Dieterich DT, Wasserman R, Bräu N, et al. Once-weekly epoetin alfa improves anemia and facilitates maintenance of ribavirin dosing in hepatitis $\mathrm{C}$ virus-infected patients receiving ribavirin plus interferon alfa. Am J Gastroenterol 2003;98:2491-9.

25. Afdhal NH, Dieterich DT, Pockros PJ, et al. Epoetin alfa maintains ribavirin dose in $\mathrm{HCV}$-infected patients: A prospective, double-blind, randomized controlled study. Gastroenterology 2004;126:1302-11.

26. Pockros PJ, Schiffman ML, Schiff ER, et al. Epoetin alfa improves quality of life in anemic HCV-infected patients receiving combination therapy. Hepatology 2004;40:1450-8.

27. Gabrilove JL, Cleeland CS, Livingston RB, Sarokhan B, Winer E, Einhorn $\mathrm{H}$. Clinical evaluation of once-weekly dosing of epoetin alfa in chemotherapy patients: Improvements in hemoglobin and quality of life are similar to three-times-weekly dosing. J Clin Oncol 2001;19:2875-82.

28. Crawford J, Cella D, Cleeland CS, et al. Relationship between changes in hemoglobin level and quality of life during chemotherapy in anemic patients receiving epoetin alfa therapy. Cancer 2002;95:888-95

29. Shiffman ML, Price A, Hubbard S, et al. Treatment of hepatitis $C$ virus (HCV) genotype 1 with peginterferon alfa-2b (PEGIFN) high weight based dose ribavirin (RVN) and epoetin alfa (EPO) enhances sustained virologic response (SVR). Hepatology 2005;42:217A. (Abst)

30. Spiegel BM, Chen K, Chiou CF, Robbins S, Younossi ZM. Erythropoietic growth factors for treatment-induced anemia in hepatitis C: A cost-effectiveness analysis. Clin Gastroenterol Hepatol 2005;3:1034-42.

31. Horl WH, Jacobs C, Macdougall I, et al. European best practice guidelines 14-16: Inadequate response to epoetin. Nephrol Dial Transplant 2000:15(Suppl 4):43-50.

32. Stravitz RT, Chung H, Sterling RK, et al. Antibody-mediated pure red cell aplasia due to epoetin alfa during antiviral therapy of chronic hepatitis C. Am J Gastroenterol 2005;100:1415-9. 


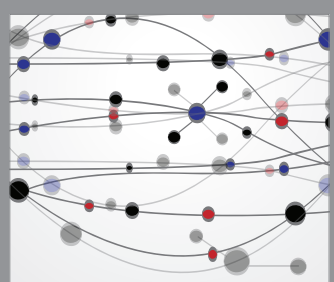

The Scientific World Journal
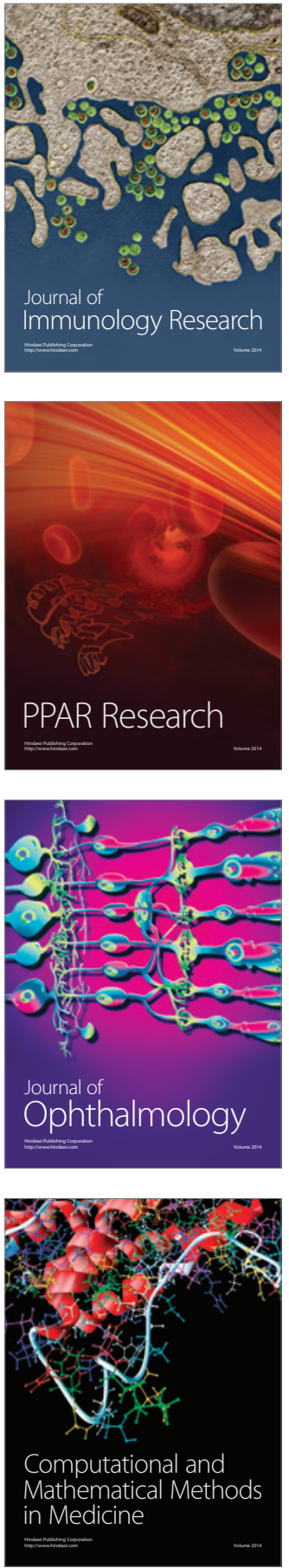

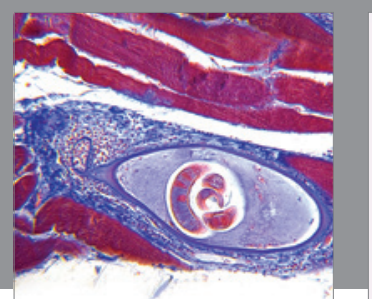

Gastroenterology Research and Practice

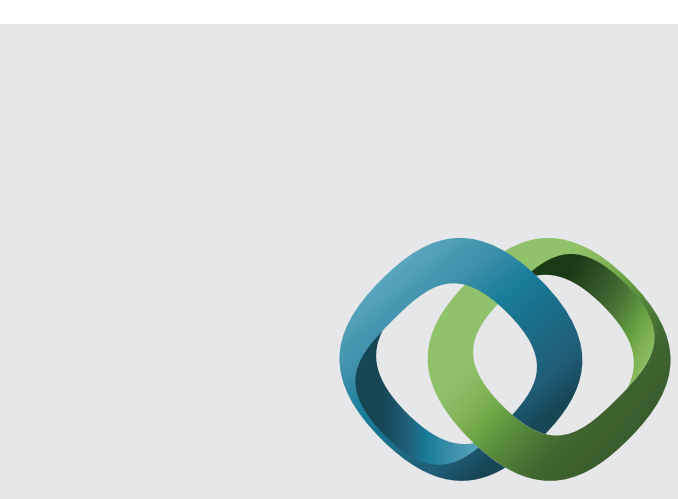

\section{Hindawi}

Submit your manuscripts at

http://www.hindawi.com
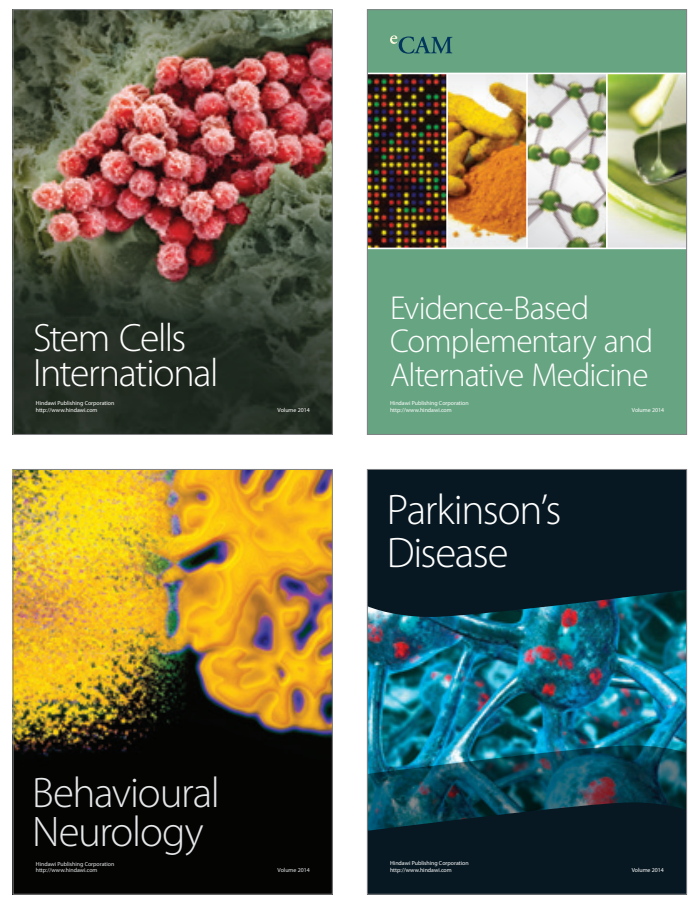
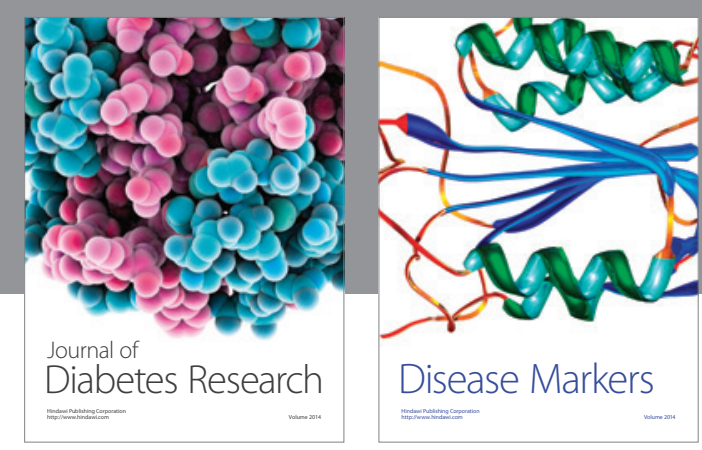

Disease Markers
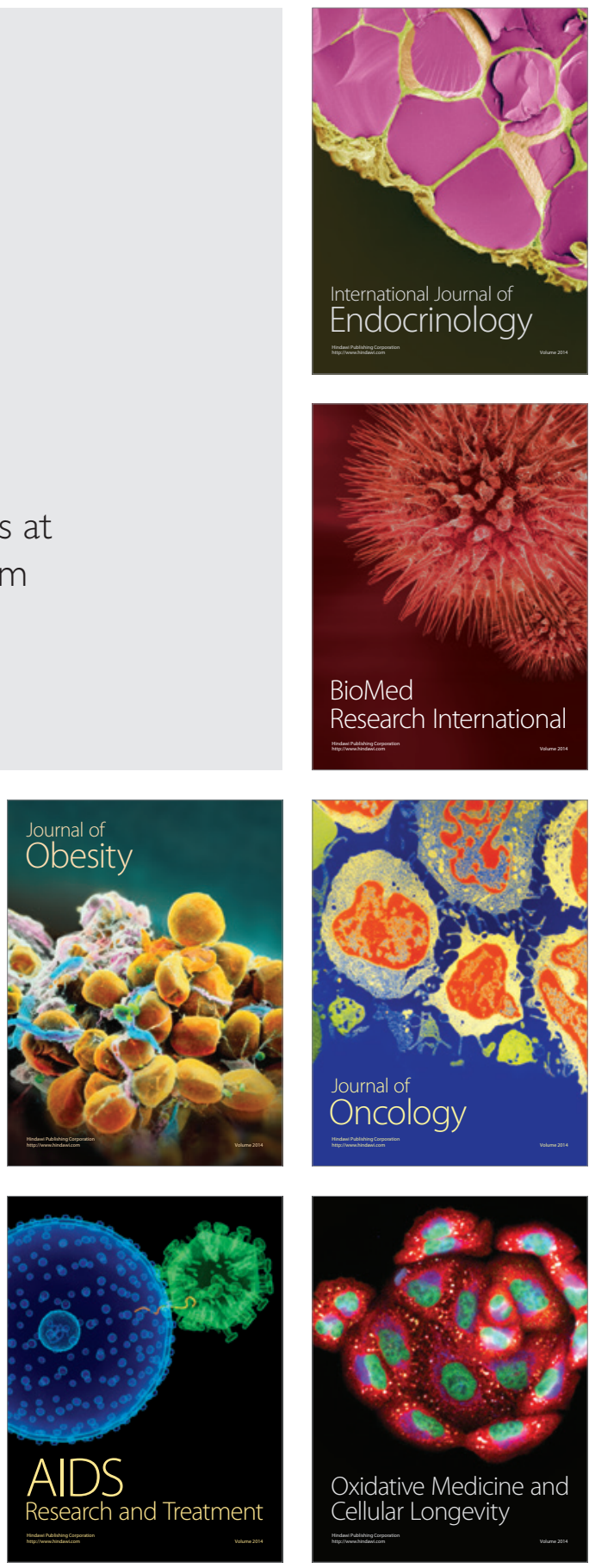